\title{
ENRAIZAMENTO DE ESTACAS APICAIS DE FIGUEIRA E DESENVOLVIMENTO INICIAL DAS PLANTAS NO CAMPO
}

\section{ROOTING OF APICAL FIG CUTTINGS AND THEIR FIRST DEVELOPMENT AT FIELD CONDITIONS}

\author{
Rafael $\mathrm{PIO}^{1}$ \\ José Darlan RAMOS² \\ Nilton Nagib Jorge CHALFUN ${ }^{2}$ \\ Edvan Alves $\mathrm{CHAGAS}^{3}$ \\ Idiana Marina DALASTRA 4 \\ Marcelo Ângelo CAMPAGNOLO ${ }^{5}$ \\ Maykon Zucari Haddad CHALFUN ${ }^{6}$
}

\begin{abstract}
RESUMO
O presente trabalho foi desenvolvido nas dependências do Setor de Fruticultura do Centro de Ciências Agrárias da Universidade Estadual do Oeste do Paraná (UNIOESTE), Marechal Cândido Rondon-PR, entre setembro de 2006 a março de 2007, com o objetivo de avaliar o desenvolvimento de figueiras no campo oriundas de estacas apicais, previamente enraizadas em viveiro através do uso de sacarose diluída em soluções de AIB, via imersão lenta. Coletaram-se estacas lenhosas da porção apical do ramo, padronizadas com $20 \mathrm{~cm}$ de comprimento, imersas em soluções sem e com sacarose a $2 \%$, diluídas em AIB (100, 200 e $300 \mathrm{mg} \mathrm{L}^{-1}$, além da testemunha sem AIB), por $24 \mathrm{~h}$. Em seguida, as estacas foram acondicionadas em recipientes de $26 \times 14 \mathrm{~cm}$, preenchidos com substrato à base de terra e areia $(2: 1 \mathrm{v} / \mathrm{v})$ e transferidas para câmara de nebulização com sistema de irrigação e temperatura controlada. Passados 60 dias realizou-se a primeira avaliação em atributos referentes ao sistema radicular e parte aérea. Uma outra parte das plantas foram transferidas para o campo em recipientes constituídos de plástico rígido com capacidade de $5 \mathrm{~L}$, preenchidos com substratos constituído de terra e esterco de curral $(3: 1 \mathrm{v} / \mathrm{v})$. Após 120 dias, constatou-se que estacas tratadas e não tratadas com sacarose e AlB na fase de enraizamento possuem comportamentos semelhantes no campo, havendo necessidade do tratamento de estacas apenas com AIB para aumentar a porcentagem de enraizamento.
\end{abstract}

Palavras-chave: Ficus carica L.; AIB; sacarose; estaquia; propagação.

\begin{abstract}
The present work was developed in the dependences of the Fruticulture Section of the Agrarian Center of Sciences, of the State University of the Paraná West (UNIOESTE), Marechal Cândido Rondon-PR, among September of 2006 to March of 2007, with the objective of evaluating the development of figs plants obtained from a rooting process of cuttings using sucrose diluted in solutions of IBA at nursery. Woody cuttings of the apical part of the branch were collected, standardized with $20 \mathrm{~cm}$ of length and immerged in solutions with or without sucrose at $2 \%$ diluted in IBA $\left(100,200,300 \mathrm{mg} \mathrm{L}^{-1}\right.$ and testimonial absentee at IBA), for 24 hours. The cuttings were transferred to recipients measuring $26 \times 14 \mathrm{~cm}$, filled with substrate composed by soil and it sand $(2: 1 \mathrm{v} / \mathrm{v})$ and stayed at nursery conditions under irrigation and temperature control. After 60 days, the roots and aerial part were evaluated. Another part of the plants were transferred to the field in recipients constituted of rigid plastic with $5 \mathrm{~L}$ of capacity, filled with a substrate composed by soil and cow mature $(3: 1 \mathrm{v} / \mathrm{v})$. After 120 days, it was verified that both the cuttings treated with sucrose and IBA or the stakes that were not treated had similar behaviors at the field and that the treatment with IBA only increased the rooting percentage.
\end{abstract}

Key-words: Ficus carica L.; IBA; sucrose; cutting; propagation.

\footnotetext{
${ }^{1}$ Eng‥ Agrônomo, D.Sc., Professor Adjunto da Universidade Estadual do Oeste do Paraná - UNIOESTE. Rua Pernambuco, no 1777 , Caixa Postal 1008, Centro, 85960-000, Marechal Cândido Rondon-PR. Bolsista Produtividade em Pesquisa CNPq. *Autor correspondente. rafaelpio@hotmail.com

2 Engํ․ Agrônomo, D.Sc., Professor Adjunto da Universidade Federal de Lavras - UFLA. Depto. de Agricultura, Caixa Postal 37, 37200-000, Lavras-MG. Bolsista Produtividade em Pesquisa CNPq. darlan@ufla.br nchalfun@ufla.br

${ }^{3}$ Engํ․ Agrônomo, D.Sc., Pesquisador Científico, Centro de Frutas/Instituto Agronômico - IAC. Av. Luiz Pereira dos Santos, 1500, Corrupira, 13214-820, Jundiaí-SP. echagas@iac.sp.gov.br

${ }^{4}$ Engํ․ Agrônomo, Mestrando do Curso de Pós-graduação em Agronomia, Universidade Estadual do Oeste do Paraná - UNIOESTE. Rua Pernambuco, no 1777, Caixa Postal 1008, Centro, 85960-000, Marechal Cândido Rondon-PR. ididalastra@yahoo.com.br

${ }^{5}$ Biólogo, Mestrando do Curso de Pós-graduação em Agronomia, Universidade Estadual do Oeste do Paraná - UNIOESTE. Rua Pernambuco, no 1777, Caixa Postal 1008, Centro, 85960-000, Marechal Cândido Rondon-PR. campa bio@yahoo.com.br

${ }^{6}$ Graduando do curso de Biologia, UNILAVRAS, Lavras-MG.
} 
$\mathrm{PIO}, \mathrm{R}$. et al. Enraizamento de estacas apicais de figueira...

\section{INTRODUÇÃO}

A figueira (Ficus carica L.), apesar de ser considerada uma frutífera de clima temperado, possui ampla adaptação a diversidade climática, podendo ser cultivada desde as regiões mais frias do Estado do Rio Grande do Sul, até regiões mais quentes, como o Norte e Nordeste brasileiro. Esta cultura tem-se mostrado excelente alternativa na diversificação de propriedades rurais, permitindo melhor aproveitamento das áreas e mostrando ser uma cultura altamente rentável, principalmente para a produção de figos verdes para a industrialização (CHALFUN et al., 1997).

Dentre os diversos aspectos técnicos envolvidos na ficicultura, destaca-se, entre outras, a dificuldade de manejo da cultura, devido principalmente à implantação do pomar, realizado através do processo de estaquia, método de propagação mais utilizado nesta cultura. Normalmente, são utilizados pelos produtores materiais oriundos da poda hibernal (julhosetembro), aproveitando apenas as estacas dotadas de 1,5 a $3,0 \mathrm{~cm}$ de diâmetro e 30 a $40 \mathrm{~cm}$ de comprimento, colocando-as diretamente na cova de plantio. Devido a não coincidência da poda hibernal com o período chuvoso, esta prática propicia um vingamento na ordem de $60 \%$ das estacas, gerando desuniformidade no figueiral (GONÇALVES et al., 2006), descartando-se o restante do material propagativo devido a sua não utilização.

A formação de mudas em recipientes vem a ser uma excelente alternativa para a formação de figueirais, podendo ainda aproveitar todo o material pertinente da poda hibernal, principalmente as porções menores localizadas nas extremidades dos ramos, o que facilitaria o manejo destas no viveiro (CHALFUN e HOFMANN, 1997; PIO et al., 2006a; 2006b).

Alguns tratamentos prévios podem favorecer a formação de raízes em estacas que apresentam baixa capacidade de enraizamento. Dentre estes, pode-se citar a aplicação exógena de reguladores de crescimento (FACHINELLO et al., 1995). O AIB é o regulador de crescimento mais comumente utilizado na indução do enraizamento adventício, por se tratar de uma substância fotoestável, de ação localizada e menos sensível à degradação biológica, em comparação as demais auxinas sintéticas (FACHINELLO et al., 2005; PASQUAL et al., 2001). É de extrema importância a utilização correta das concentrações de reguladores de crescimento a serem aplicados a base das estacas, sendo que a concentração ideal varia com a espécie em que se está trabalhando, existindo casos em que a aplicação destas substâncias pode inibir o enraizamento (HARTMANN et al., 2002).

O conteúdo de carboidratos endógenos presentes nas estacas pode ser um fator limitante durante o processo de enraizamento, podendo, dessa forma, o suprimento exógeno contribuir de forma benéfica. A adição de sacarose à solução com auxina pode apresentar um efeito benéfico ao enraizamento de estacas por constituir fonte de energia necessária para a divisão celular e emissão das raízes adventícias, podendo haver um efeito sinérgico entre auxina/sacarose no enraizamento de estacas (CHALFUN et al., 1992). A relação C/N (carbono/nitrogênio) é um outro fator importante na propagação por estaquia, onde relações elevadas propiciam um maior enraizamento, mas com pequeno desenvolvimento da parte aérea. De acordo com CASTRO e SILVEIRA (2003), a relação $\mathrm{C} / \mathrm{N}$ é importante na habilidade de enraizamento da estaca, pois, experimentos demonstram que segmentos contendo alta relação $\mathrm{C} / \mathrm{N}$ enraízam melhor, em relação aos de baixa relação $\mathrm{C} / \mathrm{N}$, devido ao baixo teor de nitrogênio e, conseqüentemente, maior concentrações de compostos relacionados com o enraizamento. Segundo FACHINELLO et al. (1998), a quantidade desses nutrientes depende do material utilizado, não se obtendo respostas satisfatórias na tentativa de adequação dessa relação. JANICK (1966) relata que níveis mais elevados de carboidratos estão diretamente relacionados com maior crescimento radicular das estacas. Segundo FACHINELLO et al. (2005), reservas mais abundantes de carboidratos correlacionam-se com maiores porcentagens de enraizamento e sobrevivência das estacas, devido a auxina requerer uma fonte de carbono para a biossíntese de ácidos nucléicos e proteínas.

O acompanhamento no desenvolvimento das plantas oriundo dessa técnica no campo poderá validar essa alternativa de propagação da figueira, podendo contribuir na implantação adequada dessa cultura, favorecendo tanto produtores de frutos como viveiristas, aumentando, assim, a eficiência do processo produtivo da cultura.

Desta forma, o presente trabalho foi desenvolvido com a finalidade de estudar a aplicação de ácido indolbutírico e sacarose na base de estacas apicais de figueira, cv. Roxo de Valinhos, estudando-se os padrões de enraizamento e desenvolvimento das brotações, bem como acompanhar o desenvolvimento inicial das plantas obtidas em condições de campo.

\section{MATERIAL E MÉTODOS}

O presente ensaio foi desenvolvido nas dependências do Setor de Fruticultura do Centro de Ciências Agrárias da Universidade Estadual do Oeste do Paraná (UNIOESTE), situada no município de Marechal Cândido Rondon-PR, no período de setembro de 2006 a março de 2007.

As estacas lenhosas utilizadas para a execução do ensaio foram retiradas da porção apical de plantas de um pomar comercial situado no município de Lavras, aproveitando o material retirado da poda de inverno. As estacas foram padronizadas com $20 \mathrm{~cm}$ de comprimento, ausentes de folhas, tendo $2,5 \mathrm{~cm}$ de suas bases imersas em soluções sem ou com sacarose a $2 \%$ diluídas em AIB (100, 200 e $300 \mathrm{mg} \mathrm{L}^{-1}$, além da testemunha sem AIB, apenas imersa em água), por $24 \mathrm{~h}$ na ausência de luminosidade.

$\mathrm{Na}$ primeira fase do experimento, as estacas foram plantadas em sacolas plásticas de 
$26 \times 14 \mathrm{~cm}$, preenchidas com substrato à base de terra e areia $(2: 1 \mathrm{v} / \mathrm{v})$ e transferidas para câmara de nebulização, com sistema de irrigação e temperatura controlada (UR de $100 \%$ e $25 \pm 2^{\circ} \mathrm{C}$ ). O delineamento utilizado foi inteiramente casualizado - DIC, em fatorial $2 \times 4$ (sacarose $\times$ AIB), contendo 4 repetições e unidade experimental composta por 10 estacas. As avaliações dos tratamentos foram realizadas 60 dias após a instalação do ensaio, através de coleta dos seguintes dados biométricos: porcentagem de estacas enraizadas, comprimento da maior raiz, número de brotações, comprimento médio das brotações e biomassa seca das brotações e das raízes.

Na segunda fase do experimento, separouse uma parte das mudas, onde estas foram aclimatadas em um telado constituído de sombrite $50 \%$ por três dias, selecionando-se a brotação mais vigorosa e desbastando as demais. Em seguida, transferiram-se as mesmas para recipientes constituídos de plástico rígido com capacidade de 5 $\mathrm{L}$, preenchidos com substratos constituídos por terra e esterco de curral (3:1 v/v) enriquecidos com 7,6 g de superfosfato simples por recipiente, sendo colocados nas entre-linhas de um plantio de figueira, buscando uma condição de ambiente mais próxima possível à de campo. Foi utilizado o delineamento experimental inteiramente casualizado - DIC, no esquema fatorial $2 \times 4$ (sacarose $x$ AIB), com 4 repetições e unidade experimental composta de cinco plantas sendo três plantas úteis.

As plantas foram irrigadas três vezes por semana com regador ( $\left.1 \mathrm{~L}_{\text {planta }}{ }^{-1}\right)$, desbrotadas periodicamente visando preservar a única brotação e adubadas com 4,25 g de sulfato de amônio e 1,15 $\mathrm{g}$ de cloreto de potássio, divididos em 4 aplicações de cobertura espaçadas de vinte dias, sendo iniciadas vinte dias após a transferência das plantas para o campo. Após 120 dias, coletaram-se os seguintes dados biométricos: número de folhas, altura da parte aérea, comprimento médio das raízes, volume radicular e biomassa seca da parte aérea e das raízes.

Os dados experimentais foram submetidos à análise de variância, as médias ao teste Tukey e os níveis de AIB à regressão, ao nível de $5 \%$ de probabilidade. A análise foi realizada pelo programa computacional Sistema para Análise de Variância SISVAR.

\section{RESULTADOS E DISCUSSÃO}

$\mathrm{Na}$ primeira fase do experimento, constatou-se que houve efeito significativo na interação entre sacarose e os diferentes níveis de AIB apenas para a variável comprimento da maior raiz. Houve diferença significativa para as variáveis porcentagem de enraizamento e biomassa seca das raízes quanto a utilização de sacarose junto as soluções de AIB e houve diferença significativa entre os níveis de AIB para todas as variáveis em estudo.

Através da Figura 1a, nota-se que houve um acréscimo na porcentagem de estacas enraizadas com o aumento das dosagens de AIB até a concentração de $194,7 \mathrm{mg} \mathrm{L}^{-1}$, obtendo-se $92,17 \%$ de estacas enraizadas. A partir dessa concentração, houve um decréscimo na porcentagem de enraizamento. Esse comportamento pode estar relacionado ao fato do suprimento exógeno de AIB promover ganhos significativos até uma certa concentração, devido à carência de tal substância endogenamente na estaca, onde à partir desse ponto, pode ter ocorrido excesso da concentração de auxina na base da estaca e ter ocorrido fitotoxidez, ocorrendo, conseqüentemente, queda na porcentagem de enraizamento. Esses resultados vêm a discordar de NOGUEIRA et al. (2007), que obteve um índice de $72,29 \%$ de estacas enraizadas na ausência de AIB. Esta diferença está associada ao fato deste autor utilizar estacas herbáceas e oriundas da porção basal dos ramos de figueira para a execução de seu trabalho.

Para a variável comprimento da maior raiz (Figura 1b), verifica-se que a ausência de sacarose e AIB propiciaram um comprimento de $8,06 \mathrm{~cm}$ da maior raiz. Porém, com a utilização de sacarose verificou-se um incremento de $2,08 \mathrm{~cm}$, obtendo-se assim o comprimento da maior raiz de $10,14 \mathrm{~cm}$. Isso pode estar relacionado ao fato do suprimento exógeno da estaca com sacarose ter suprido certas deficiências internas da estaca, em relação aos carboidratos, substâncias essenciais ao enraizamento, que poderiam estar limitando o maior desenvolvimento da raiz. Segundo HESS (1969), os

TABELA 1 - Porcentagem de estacas enraizadas (\% EE), número de brotações (NB), comprimento médio das brotações $(\mathrm{CMB}, \mathrm{cm})$ e biomassa seca das brotações (BSB, mg) e das raízes (BSR, mg) através do uso de sacarose a $2 \%$ diluída nas soluções de AIB aplicadas por imersão lenta no enraizamento de estacas apicais de figueira. Marechal Cândido Rondon, UNIOESTE, 2007.

\begin{tabular}{|c|c|c|c|c|c|}
\hline & \multicolumn{5}{|c|}{ Variáveis analisadas* } \\
\hline & $\% \mathrm{EE}$ & NB & CMB & BSB & BSR \\
\hline Sem sacarose & $79,06 \quad b$ & $3,58 \mathrm{a}$ & $3,12 \mathrm{a}$ & $487,14 \mathrm{a}$ & $310,08 \mathrm{a}$ \\
\hline Com sacarose & $87,50 \mathrm{a}$ & $3,94 \mathrm{a}$ & $3,46 \mathrm{a}$ & $551,97 \mathrm{a}$ & 259,49 b \\
\hline C.V. (\%) & 11,61 & 17,03 & 15,29 & 17,93 & 19,26 \\
\hline
\end{tabular}

* Médias seguidas da mesma letra na coluna, não diferem significamente entre si pelo teste Tukey à $5 \%$ de probabilidade. 
PIO, R. et al. Enraizamento de estacas apicais de figueira...

carboidratos possuem relação direta com incrementos no potencial de enraizamento das estacas. Efeitos positivos da presença de sacarose pode ser verificado na Tabela 1, obtendo-se $87,50 \%$ de estacas enraizadas com a utilização de sacarose contra 79,06\% em sua ausência. Analisando-se ainda a mesma Tabela, nota-se um efeito negativo da utilização de sacarose para a variável biomassa seca das raízes, obtendo-se $310,08 \mathrm{mg}$ contra $259,49 \mathrm{mg}$ na sua presença.

a

b
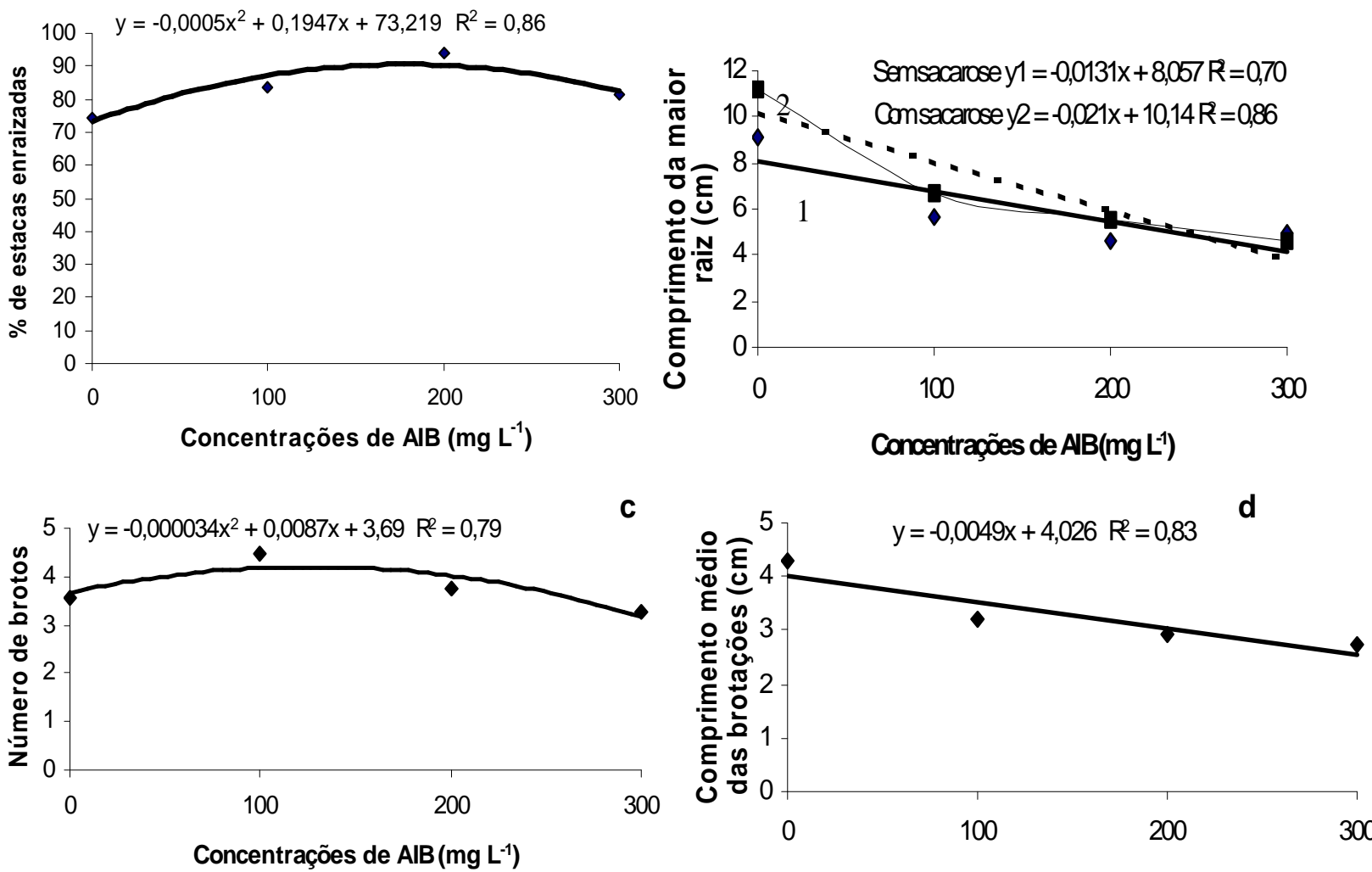

Concentrações de AIB (mg L $\left.\mathrm{L}^{-1}\right)$
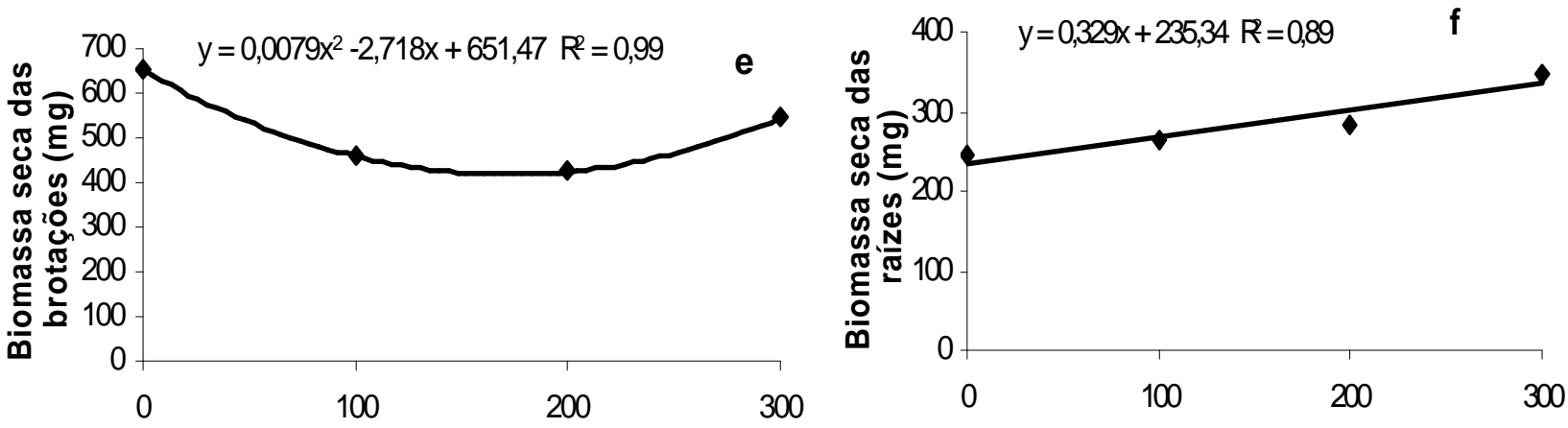

Concentrações de $\mathrm{AlB}\left(\mathrm{mg} \mathrm{L}^{-1}\right)$

FIGURA 1 - Porcentagem de estacas enraizadas (a), comprimento da maior raiz (b), número de brotos (c), comprimento médio das brotações (d), biomassa seca das brotações (e) e raízes (f) através do uso de sacarose a $2 \%$ diluída nas soluções de AIB no enraizamento de estacas apicais de figueira. Marechal Cândido Rondon, UNIOESTE, 2007. 
Observando-se a Figura 1c, verifica-se que maior número de brotações foi obtido com 121,94 $\mathrm{mg} \mathrm{L}^{-1}$ de AIB (4,25 brotos). Para o comprimento médio das brotações (Figura 1d), a ausência de AIB propiciou melhores resultados $(4,29 \mathrm{~cm})$. Para a biomassa seca das brotações e das raízes (Figuras 1e e 1f), os melhores resultados foram obtidos com a testemunha sem AIB e $300 \mathrm{mg} \mathrm{L}^{-1}$ de AIB $(652 \mathrm{mg}$ e $348,40 \mathrm{mg}$, respectivamente). Esses resultados discordam com os de ANTUNES et al. (1996), que verificou que a concentração de $100 \mathrm{mg} \mathrm{L}^{-1}$ de AIB proporcionou melhores resultados para as variáveis biomassa seca das brotações e das raízes. Essa discordância pode estar relacionada ao fato deste autor ter utilizado estacas coletadas no mês de julho, o que pode eventualmente possuir outros níveis de exigência hormonal para a promoção do enraizamento. Alguns trabalhos vêm mostrando os efeitos da aplicação exógena de auxinas em muitas espécies, no entanto, dependo da concentração e da época de coleta das estacas, poderá ter efeito inibitório ou fitotóxico (PIO et al. 2008). Comparandose a Figura $1 \mathrm{~b}$ (comprimento da maior raiz da estaca) com a Figura if (biomassa seca das raízes), notase que a testemunha ausente de AIB promoveu o maior comprimento da raiz, ocorrendo uma ligeira queda linear, quando se submeteram as estacas nas crescentes concentrações da referida auxina. Porém, o comportamento da biomassa seca das raízes foi o inverso, ocorrendo um aumento linear na presença de concentrações crescentes de AIB até a concentração de $300 \mathrm{mg} \mathrm{L}^{-1}$. Por estes resultados, pode-se notar que o AIB promove uma maior emissão de raízes adventícias nas estacas, aumentando o número e o peso das raízes emitidas, proporcionando assim uma maior biomassa seca das raízes. Por outro lado, a ausência de AIB favorece o alongamento das raízes formadas à base das estacas, frisando que possivelmente essas raízes são em menor número devido ocorrer uma menor biomassa seca das raízes sem o tratamento com essa auxina, mas como nesse caso, única e exclusivamente, as raízes são formadas apenas pela quantidade de reservas presentes endógenamente nas estacas, as reservas limitamse a favorecer o pequeno número de raízes formadas, ocorrendo, assim, maior alongamento das raízes.

$\mathrm{Na}$ avaliação da segunda fase do experimento, verificou-se que não houve diferença significativa para todas as características analisadas neste trabalho.

Pela Tabela 2 pode-se verificar que a presença de sacarose na fase de enraizamento, não influenciou em ganhos no desenvolvimento das mudas no campo a tal ponto que possa ser recomendada sua utilização na propagação de estacas apicais de figueira, pelo fato das plantas tratadas ou não com esta substância não diferirem entre si. Observando a Tabela 3 , verifica-se que a presença das crescentes concentrações da auxina AIB na fase de enraizamento, não promoveu ganhos significativos na qualidade do sistema radicular e da parte aérea das figueiras, pelo fato das plantas no campo, tratadas ou não com AIB, propiciarem comportamentos semelhantes quanto às características analisadas. Por estes resultados, nota-se que mesmo podendo haver diferenças na fase de enraizamento, no momento da iniciação da promoção radicular, estas diferenças são amenizadas posteriormente no desenvolvimento das plantas no campo. Segundo HINOJOSA (2000), reguladores de crescimento favorecem o estímulo da iniciação radicular, proporcionando aumento da porcentagem de estacas enraizadas, bem como aceleração da formação de raízes.

TABELA 2 - No folhas (NF), altura da parte aérea (APA, cm), comprimento médio das raízes (CMR, cm), volume radicular $\left(\mathrm{VR}, \mathrm{cm}^{3}\right.$ ) e biomassa seca da parte aérea (BSA, g) e das raízes (BSR, g) de plantas de figueira submetidas ao tratamento de sacarose a $2 \%$ diluída em soluções de AIB aplicadas por imersão lenta no enraizamento de suas estacas. Marechal Cândido Rondon, UNIOESTE, 2007.

\begin{tabular}{ccccccc}
\hline & \multicolumn{5}{c}{ Variáveis analisadas $^{*}$} \\
\cline { 2 - 7 } & NF & APA & CMR & VR & BSA & BSR \\
\hline Sem sacarose & $7,25 \mathrm{a}$ & $39,25 \mathrm{a}$ & $25,31 \mathrm{a}$ & $44,81 \mathrm{a}$ & $15,69 \mathrm{a}$ & $5,06 \mathrm{a}$ \\
Com sacarose & $7,31 \mathrm{a}$ & $41,31 \mathrm{a}$ & $25,06 \mathrm{a}$ & $49,06 \mathrm{a}$ & $15,06 \mathrm{a}$ & $5,44 \mathrm{a}$ \\
\hline C.V. $(\%)$ & 10,95 & 12,57 & 20,14 & 19,79 & 37,52 & 28,97 \\
\hline
\end{tabular}

* Médias seguidas da mesma letra na coluna, não diferem significamente entre si pelo teste Tukey à $5 \%$ de probabilidade.

TABELA 3 - No folhas (NF), altura da parte aérea (APA, cm), comprimento médio das raízes (CMR, cm), volume radicular $\left(\mathrm{VR}, \mathrm{cm}^{3}\right)$ e biomassa seca da parte aérea (BSA, g) e das raízes (BSR, g) de plantas de figueira submetidas a diferentes tratamento de AIB por imersão lenta no enraizamento de suas estacas. Marechal Cândido Rondon, UNIOESTE, 2007.

\begin{tabular}{|c|c|c|c|c|c|c|}
\hline \multirow[b]{2}{*}{ AIB $\left(\mathrm{mg} \mathrm{L}^{-1}\right)$} & \multicolumn{6}{|c|}{ Variáveis analisadas* } \\
\hline & NF & APA & CMR & VR & BSA & BSR \\
\hline 0 & $7,88 \mathrm{a}$ & $42,62 \mathrm{a}$ & $28,62 \mathrm{a}$ & $49,38 \mathrm{a}$ & $20,38 \mathrm{a}$ & $5,88 \mathrm{a}$ \\
\hline 100 & $7,12 \mathrm{a}$ & $40,38 \mathrm{a}$ & $24,00 \mathrm{a}$ & $47,62 \mathrm{a}$ & $14,25 \mathrm{a}$ & $5,75 \mathrm{a}$ \\
\hline 200 & $7,00 \mathrm{a}$ & $39,62 \mathrm{a}$ & $23,75 a$ & $44,50 \mathrm{a}$ & $13,50 \mathrm{a}$ & $4,75 \mathrm{a}$ \\
\hline 300 & $7,12 \mathrm{a}$ & $38,50 \mathrm{a}$ & $24,38 \mathrm{a}$ & $46,25 \mathrm{a}$ & $13,38 \mathrm{a}$ & $4,63 \mathrm{a}$ \\
\hline C.V. (\%) & 10,95 & 12,57 & 20,14 & 19,79 & 37,52 & 28,97 \\
\hline
\end{tabular}

* Médias seguidas da mesma letra na coluna, não diferem significativamente entre si pelo teste Tukey à 5\% de probabilidade. 
PIO, R. et al. Enraizamento de estacas apicais de figueira...

Verifica-se ainda que este método de produção de mudas é viável, pelos excelentes resultados obtidos (Tabela 3 ) para as variáveis altura da parte aérea $(42,62 \mathrm{~cm})$, comprimento médio das raízes $(28,62 \mathrm{~cm})$ e biomassa seca da parte aérea $(20,38 \mathrm{~g})$ e das raízes $(5,88 \mathrm{~g})$. Os resultados obtidos neste trabalho vêm a discordar com as recomendações de NORBERTO et al. (2001), destacando que, para a formação de um figueiral, deve-se utilizar estacas provenientes preferencialmente da porção basal e mediana de ramos do ano, para se ter um bom desenvolvimento das raízes e, conseqüentemente, da parte aérea da planta.

\section{CONCLUSÕES}

Nas condições em que foi realizado o presente ensaio, permitem-se as seguintes conclusões:

1. A utilização de AIB aumenta a porcentagem de estacas enraizadas.

2. Os ganhos promovidos na qualidade do sistema radicular e da parte aérea das estacas apicais de figueira com a utilização de AIB e sacarose na fase de enraizamento, não promovem melhorias no desenvolvimento inicial das plantas.

3. A produção de mudas de figueira através de estacas apicais é um método viável.

\section{REFERÊNCIAS}

1. ANTUNES, L.E.C.; CHALFUN, N.N.J.; RAMOS, J.D.; PASQUAL, M.; VEIGA, R.D. Influencia de diferentes períodos de estratificação, concentrações de acido indolbutírico e substratos no enraizamento de estacas de figueira. Ciencia e Agrotecnologia, v. 20, p. 307-314, 1996.

2. CASTRO, L.A.S.; SILVEIRA, C.A.P. Propagação vegetativa do pessegueiro por alporquia. Revista Brasileira de Fruticultura, v. 25, n. 2, p. 368-370, 2003.

3. CHALFUN, N.N.J.; DUARTE, G.S.; PIVETTA, K.F.L.; KIAM, O.Y.; ABRAHÃO, E.; ALVARENGA, A.A. Uso de ácido indolbutírico e da sacarose no enraizamento de estacas caulinares de porta-enxertos de videira 'RR 101-14'. Ciência e Prática, v. 16, n. 3, p. 389-393, 1992.

4. CHALFUN, N.N.J.; HOFFMANN, A. Propagação da figueira. In: Informe Agropecuário, v. 18, n. 188, p. 9-13, 1997.

5. CHALFUN, N.N.J.; PASQUAL, M.; HOFFMANN, A. Fruticultura comercial: Frutíferas de clima temperado. Lavras: UFLA/FAEPE, 1997. 304 p.

6. FACHINELLO, J.C.; HOFFMANN, A.; NACHTIGAL, J.C. Propagação de plantas frutíferas. Brasília: Embrapa Informação Tecnológica, 2005. 221p.

7. FACHINELLO, J.C.; LUCCHESI, A.A.; GUTIERREZ, L.E. Influência do anelamento na nutrição e no enraizamento de estacas lenhosas do porta-enxerto 'Malling Merton 106'. Pesquisa Agropecuária Brasileira, v. 23, n. 9, p. 10251031, 1998.

8. GOLÇALVES, C.A.A.; LIMA, L.C.O.; LOPES, P.S.N.; SOUZA, M.T. Poda e sistemas de condução na produção de figos verdes. Pesquisa Agropecuária Brasileira, v. 41, n. 6, p. 955-961, 2006.

9. HARTMANN, H.T.; KESTER, D.E.; DAVIES JUNIOR, F.T.; GENEVE, R.L. Plant propagation: principles and practices. 7. ed. New Jersey: Prentice Hall, 2002. 880 p.

10. HESS, C.E. Internal and external factors regulating root iniciation. In: WHITTINGTON, W. J. (Ed.). Root growth. London: Buttewarth, 1969. p. 42-53.

11. HINOJOSA, G.F. Auxinas. In: CID, L.P.B. (Ed.). Introdução aos hormônios vegetais. Brasília: EMBRAPA, 2000. p. $15-54$.

12. JANICK, J.A. A ciência da horticultura. Rio de Janeiro: Freitas Bastos, 1966. 485 p.

13. NOGUEIRA, A.M.; CHALFUN, N.N.J.; VILLA, F.; DUTRA, L.F. Propagação de figueira (Ficus carica L.) através de estacas retiradas durante o período vegetativo. Ciência e Agrotecnologia, v. 31, p. 914-920, 2007.

14. NORBERTO, P.M.; CHALFUN, N.N.J.; PASQUAL, M.; VEIGA, R.D.; MOTA, J.H. Efeito de época de poda, cianamida hidrogenada e irrigação na produção antecipada de figos verdes. Pesquisa Agropecuária Brasileira, v. 36, n. 11, p. 1363-1369, 2001.

15. PASQUAL, M.; CHALFUN, N.N.J.; RAMOS, J.D.; VALE, M.R.do; SILVA, C.R.R. Fruticultura comercial: Propagação de plantas frutíferas. Lavras: UFLA/FAEPE, 2001. $137 \mathrm{p}$.

16. PIO, R.; OHLAND, T.; CHAGAS, E.A.; BARBOSA, W.; CAMPAGNOLO, M.A.; DALASTRA, I.M. Enraizamento de estacas radiculares de figueira 'Roxo de Valinhos' tratadas com AIB e dois métodos de imersão. Scientia Agraria, v. 9, p. 111115, 2008.

17. PIO, R.; RAMOS, J.D.; CHALFUN, N.N.J.; GONTIJO, T.C.A.; MENDONÇA, V.; CARRIJO, E.P.; CHAGAS, E.A. Propagação de estacas apicais de figueira: diferentes ambientes, ácido indolbutírico e tipo de estaca. Ciência e Agrotecnologia, v. 30 , p. 1021-1026, 2006a.

18. PIO, R.; CHAGAS, E.A.; BARBOSA, W.; MENDONÇA, V.; SCARPARE FILHO, J.A.; GUIMARAES, V.F. Enraizamento de estacas de figueira coletadas em diferentes posições no ramo e ambientes de propagação distintos. Scientia Agraria Paranaensis, v. 5 , p. $1-5,2006$ b.

Recebido em 04/10/2007 Aceito em 28/02/2008 